\title{
Uso de imagens do sensor ASTER na identificação de níveis de degradação em pastagens
}

\author{
Melchior C. Nascimento ${ }^{1}$, Rogério D. D. Riva ${ }^{2}$, César da S. Chagas ${ }^{3}$, Henrique de Oliveira ${ }^{4}$, \\ Luiz E. Dias ${ }^{5}$, Elpídio I. Fernandes Filho ${ }^{5}$ \& Vicente P. Soares
}

\begin{abstract}
RESUMO
O manejo inadequado e a baixa disponibilidade de nutrientes nos solos da Zona da Mata de Minas Gerais, têm resultado em baixas produtividades de pastagens, aparecimento de solos descobertos e perdas de solo por erosão. O objetivo deste trabalho foi avaliar a capacidade das imagens do sensor ASTER em identificar diferentes níveis de degradação de pastagens. A área de estudo inclui parte dos municípios de Viçosa, Teixeiras e São Miguel do Anta, perfazendo cerca de 3.314 ha. Devido às características das pastagens da região, foram utilizados quatro níveis de degradação: leve, moderada, forte e muito forte. A classe que apresentou maior erro de classificação foi a pastagem com nível de degradação muito forte (Pastagem 4), com 53,91\% dos pixels classificados, confundindo-se com as demais classes. A pastagem com nível de degradação moderada (Pastagem 2) apresentou a melhor classificação. Da área avaliada, aproximadamente 70\% correspondem a pastagens, sendo 56,46\% classificadas como fortemente degradadas; $28,73 \%$ Mata/Capoeira e 1,54\% plantações de café. Os resultados permitiram concluir que as imagens do sensor ASTER apresentaram um potencial satisfatório para separar os diferentes níveis de degradação de pastagens.
\end{abstract}

Palavras-chave: pastagens degradadas, sensoriamento remoto, classificação

\section{Use of ASTER sensor images for the identification of levels of pasture degradation}

\begin{abstract}
The improper management and the low availability of nutrients of soils in "Zona da Mata" in Minas Gerais State, Brazil, have led to low productivity of natural pasture, emergence of bare soils and soil losses by erosion. The objective of this work was to evaluate the capacity of ASTER sensor images to identify different levels of degradation in pasture lands. The studied area includes part of Viçosa, Teixeiras, and São Miguel do Anta municipalities, forming a total area around 3,314 ha. Due to natural characteristics of the pasture in this region, four levels of degradation were used: light, moderate, strong, and very strong. The class that showed the highest error in the classification was the very strong, degraded with $53.91 \%$ of the classified pixels, not distinguishable from the other classes. The moderate degradation class showed the best classification. From the total evaluated area, approximately $70 \%$ corresponded to pasture, $56.46 \%$ of which was classified in the strong degradation level, $28.73 \%$ to 'Mata/Capoeira' and only $1.54 \%$ to coffee plantations. The results permit to conclude that the use of sensor ASTER images was satisfactory to separate degradation levels of pasture lands in the studied area.
\end{abstract}

Key words: degraded pastures, remote sensing, classification

1 UFAL/GEM/ Av. Francisco de Menezes 1888, Bom Parto, CEP 57017-315, Maceió, AL. Fone (82) 3336-5937. mgeop@ig.com.br 2 UNEMAT/DCB-AF. Rod. MT 208, km 147, Jardim Tropical, CP 324, CEP 78580000, Alta Floresta, MT. Fone (66) 521-2041. riva@unemat.br ${ }_{3}^{3}$ Embrapa Solos. Rua Jardim Botânico 1024, Jardim Botânico, CEP 22460000, Rio Janeiro, RJ. Fone (21) 2274-4999. cschagas@uai.com.br ${ }^{4}$ Embrapa Pantanal. Rua 21 de Setembro 1880, Aeroporto, CEP 79320900, Corumbá, MS. Fone (67)233-2430. henrique@cpap.embrapa.br ${ }^{5}$ UFV/DPS. UFV, CEP 36570000, Viçosa, MG. Fone (31) 3899-1040. led@ufv.br; elpidio@ufv.br e vicente@ufv.br 


\section{INTRODUÇÃO}

Na Zona da Mata mineira, devido ao intenso desmatamento a que a região foi submetida para o estabelecimento da cafeicultura e, posteriormente, com o seu declínio, constatou-se o predomínio da utilização das terras com pastagens que ocupam desde o topo das elevações até a área de inundação dos cursos d'água (Pimentel et al., 1982; Quinteiro, 1997). A espécie Melinis minutiflora, Beauv. (capim gordura ou capim melado) é a gramínea dominante na região e exerceu, durante muito tempo, significativo papel na proteção dos solos contra a erosão; é considerada planta tolerante à baixa fertilidade do solo e à moderada deficiência hídrica; entretanto, é muito sensível ao pisoteio excessivo, a cortes freqüentes e ao fogo, podendo desaparecer quando este for freqüente (Quinteiro, 1997; Carvalho, 1998).

Vários são os fatores que contribuem para a degradação das pastagens. Na Zona da Mata mineira o manejo inadequado e as deficiências nutricionais do solo são os fatores que mais concorrem para a redução de sua produtividade, em conseqüência, surgindo áreas descobertas, povoadas por invasoras de folhas largas ou por gramíneas de baixo valor forrageiro. Nos casos mais extremos, a redução na cobertura do solo pela gramínea se acentua e as perdas de solo por erosão são facilitadas, originando os chamados "pelados" (Baruqui, 1982; Carvalho, 1998).

Nascimento Júnior et al. (1994) consideram que o estabelecimento de critérios de degradação das pastagens é tarefa bastante difícil, tendo em vista a diversidade das espécies com relação às suas características morfológicas e aos ecossistemas em que são cultivadas; no entanto, alguns estágios de degradação podem ser facilmente identificados e são próprios da maioria das pastagens degradadas, que são: distúrbio físiológico da espécie dominante, mudança na composição botânica e invasão por novas espécies, que levam a uma redução na qualidade e na quantidade da pastagem e, em estágios mais avançados, ao desaparecimento da espécie dominante e também das invasoras, comprometendo as condições de estabilidade do solo.

Segundo Sano et al. (2000), a recuperação de pastagens degradadas é de difícil implementação devido à falta de informações atualizadas e detalhadas a respeito de sua distribuição espacial. O sensoriamento remoto, em virtude do seu baixo custo, repetitividade e escala compatível, pode contribuir, em muito, para subsidiar políticas de recuperação de pastagens degradadas, em diferentes regiões.

As tentativas para mapear pastagens a partir da análise de imagens de satélite em regiões tropicais e subtropicais, freqüentemente têm sucesso limitado. Nessas regiões, as pastagens podem ter respostas espectrais similares às florestas e à cana-de-açúcar (Price et al., 1992; Hernandez et al., 1998). Neste sentido, Assad et al. (1991) destacam a necessidade de estudos radiométricos de campo para estabelecer o comportamento espectral dos diferentes alvos estudados.

Sano et al. (2000) utilizaram imagens do Landsat-7 e do Radarsat na identificação dos principais tipos de pastagem cultivada na região do Cerrado do Distrito Federal. A análise radiométrica permitiu, em associação com a análise da imagem Landsat, a separação de dois grandes grupos de pastagens da região, por gênero (Andropogon e Panicum), utilizando principalmente as bandas 3 e 4 . Por outro lado, a análise das imagens do Radarsat possibilitou a discriminação das pastagens de Brachiaria brizantha, Panicum maximum cv. Tanzânia e Brachiaria decumbens com nível intermediário de degradação.

Ainda na região do Distrito Federal, Moreira \& Assad (2000) adotaram técnicas de segmentação e classificação supervisionada em imagens do satélite Landsat-5 para identificação de áreas de pastagem com diferentes níveis de degradação, cujos resultados mostraram que a sua utilização foi eficiente para a separação da área em classes de uso da terra, bem como na identificação de cinco níveis de degradação das pastagens.

Assim, este estudo objetivou avaliar a eficiência da análise e processamento digital das imagens do sensor ASTER, na identificação de diferentes níveis de degradação das pastagens em uma área na Zona da Mata de Minas Gerais. Seus resultados poderão subsidiar a instalação de um programa de recuperação de pastagens degradadas racional contribuindo, desta forma, para a mitigação dos impactos ambientais negativos advindos da degradação dessas áreas.

\section{MATERIAL E MÉTODOS}

A área estudada para a avaliação do potencial das imagens do sensor ASTER na identificação dos níveis de degradação das pastagens, está localizada entre as coordenadas $20^{\circ} 39^{\prime} 41^{\prime \prime}$ e $20^{\circ} 42^{\prime} 42^{\prime \prime}$ de Latitude Sul e $42^{\circ} 49^{\prime} 58^{\prime \prime}$ e $42^{\circ} 46^{\prime} 32^{\prime \prime}$ de Longitude Oeste, englobando parte dos municípios de Viçosa, Teixeiras e São Miguel do Anta (Figura 1).

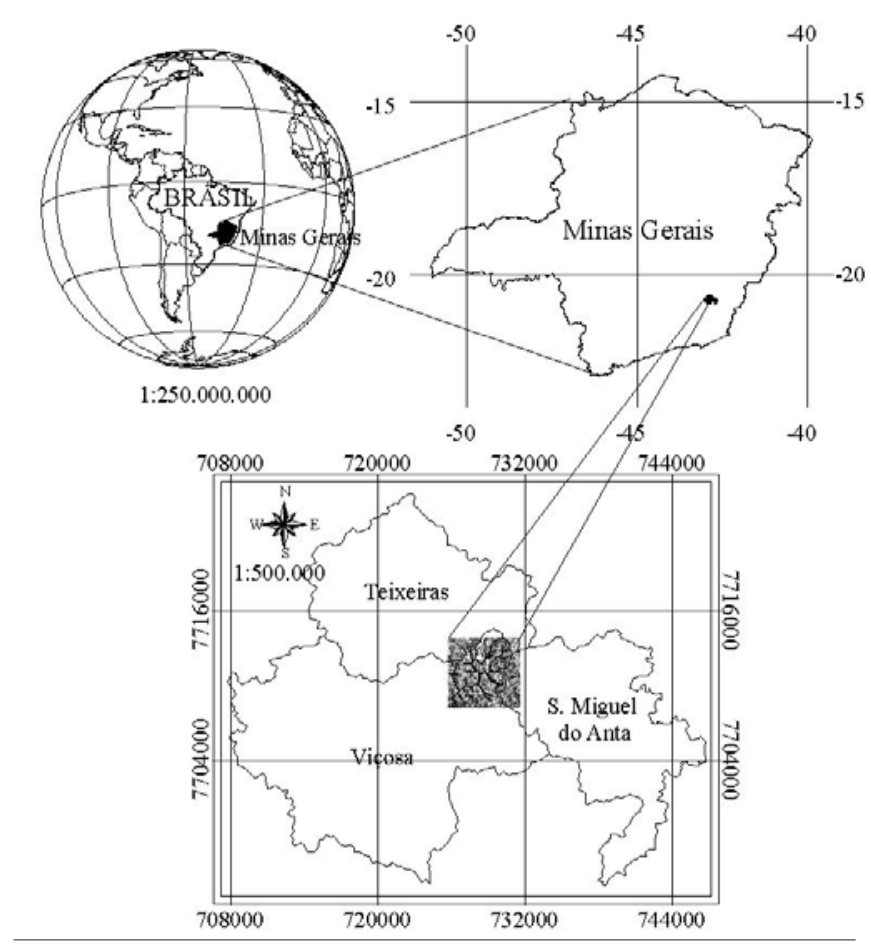

Figura 1. Localização da área estudada 
Tabela 1. Níveis de degradação de pastagens utilizados

\begin{tabular}{|c|c|c|}
\hline Níveis de degradação & Parâmetros Limitantes & Deterioração \\
\hline Pastagem 1 & Bom vigor e boa qualidade & Leve \\
\hline Pastagem 2 & Baixo vigor, qualidade e baixa população & Moderado \\
\hline Pastagem 3 & $\begin{array}{l}\text { Baixo vigor, qualidade e baixa população, } \\
\text { associado com a presença de invasoras } \\
\text { e/ou cupins }\end{array}$ & Forte \\
\hline Pastagem 4 & $\begin{array}{l}\text { Baixo vigor, qualidade e baixa população, } \\
\text { associado com a presença de invasoras, } \\
\text { cupins e solo descoberto }\end{array}$ & Muito forte \\
\hline
\end{tabular}

Assim como toda a região da Zona da Mata de Minas Gerais, a área de estudo também é caracterizada por um relevo acidentado, com altitude média de $650 \mathrm{~m}$, apresentando poucas áreas planas. O clima se enquadra no tipo Cwa (inverno seco e verão chuvoso), de acordo com a classificação de Köppen, com temperatura do mês mais frio inferior a $18^{\circ} \mathrm{C}$ e, do mês mais quente, superior a $22{ }^{\circ} \mathrm{C}$, com precipitação média anual de $1203 \mathrm{~mm}$ (Golfari, 1975).

De maneira geral, predominam na região os Latossolos Vermelho-Amarelos, que ocupam os topos convexos da paisagem; os Cambissolos, nas partes mais íngremes e côncavas, em que o horizonte $\mathrm{C}$ está mais próximo da superfície e os Argissolos Vermelho-Amarelos, nos terraços (Naime, 1988; Carvalho Filho, 1989).

A imagem ASTER (Advanced Spaceborne Thermal Emission and Reflection Radiometer) utilizada foi a composição colorida 3R2G1B (0,50-0,90 mm), com resolução espacial de 15 m, obtida em 05/04/2001, que coincide com o início da estação seca. Além da imagem também foram adotados, neste estudo: o mapa planialtimétrico, gerado a partir da digitalização das curvas de nível da Folha SF23-X-B-V-1 (Teixeiras) do IBGE; o mapa da hidrografia, ambos na escala de 1:50.000; os softwares ArcView, versão 3.2a (ESRI, 1996) e ENVI, versão 3.5 (Research System, 2001).

A cobertura vegetal do solo e outros componentes do meio biótico, como revegetação por espécies nativas e exóticas e termiteiros, têm sido, juntos, bastante utilizados como indicadores do processo de perda da capacidade produtiva das pastagens (Spain \& Gualdrón, 1991; Barcellos et al., 1997; Moreira \& Assad, 2000). Desta maneira e se levando em consideração as características das pastagens da região da Zona da Mata de Minas Gerais, com predominância da espécie Melinis minutiflora, Beauv, e os indicadores visuais de degradação, estabeleceram-se quatro níveis de degradação, conforme apresentado na Tabela 1.

Antecedendo a etapa de classificação, aplicou-se o filtro gaussiano (Gaussian Low Pass), disponível no software ENVI, utilizando-se uma máscara do tipo passa-baixa $3 \times 3$, com o objetivo de se obter uma suavização (smoothing) das altas freqüências da imagem, sem afetar perceptivelmente as bordas das feições de interesse.

A classificação supervisionada foi realizada selecionandose amostras das classes de interesse observadas na área de estudo, ou seja: mata/capoeira, cafezal, solo exposto, pastagem no nível de degradação moderado (Pastagem 2), pastagem no nível de degradação forte (Pastagem 3) e pastagem no nível de degradação muito forte (Pastagem 4). A seguir, a imagem foi classificada utilizando-se o algoritmo classificador distância de Mahalanobis.

O nível de confiança da classificação foi verificado por meio da matriz de erros pela seleção de dois conjuntos de classes, sendo um de treinamento e outro de teste. O conjunto de treinamento visou à classificação para futura comparação e o conjunto de teste foi selecionado com o objetivo de gerar a matriz de erros. A avaliação da classificação através da matriz de erros, usando o índice de exatidão Kappa, considera a proporção de amostras corretamente classificadas (exatidão total) correspondentes à razão entre a soma da diagonal principal da matriz de erros (amostras corretamente classificadas) e a soma de todos os elementos desta matriz (número total da amostra) tendo como referência o número total de classes (Cohen, 1960, apud Rosenfield \& Fitzpatrick-Lins, 1986).

Após a etapa de classificação, realizaram-se novos levantamentos de campo para verificação dos resultados obtidos, visando contornar possíveis erros no processo de classificação. Os resultados finais foram processados no ArcView, versão $3.2 \mathrm{a}$, onde se realizaram as seguintes operações: reclassificações, cruzamentos e análises espaciais, para edição final do mapa.

\section{RESULTADOS E DISCUSSÃO}

O resultado obtido com a utilização do estimador de acerto Kappa (matriz de erros), para a classificação realizada, foi de 0,83 , valor considerado excelente $(0,8<\mathrm{K} \leq 1)$ (Brites et al., 1996; Foody, 1992), indicando que a proporção de

Tabela 2. Resultado da classificação pelo estimador de acerto de Kappa

\begin{tabular}{|c|c|c|c|c|c|c|c|}
\hline Classes & Cafezal & Mata/capoeira & Solo exposto & Pastagem 2 & Pastagem 3 & Pastagem 4 & Total \\
\hline Cafezal & 99 & 0 & 2 & 0 & 0 & 3 & 104 \\
\hline Mata/capoeira & 0 & 894 & 0 & 5 & 12 & 0 & 911 \\
\hline Solo exposto & 0 & 0 & 525 & 0 & 0 & 301 & 826 \\
\hline Pastagem 2 & 0 & 0 & 1 & 692 & 1 & 1 & 695 \\
\hline Pastagem 3 & 0 & 0 & 12 & 9 & 623 & 33 & 677 \\
\hline Pastagem 4 & 2 & 0 & 99 & 4 & 63 & 289 & 457 \\
\hline Total & 101 & 894 & 639 & 710 & 699 & 627 & 3670 \\
\hline & & & & & \multicolumn{2}{|c|}{ Coeficiente Kappa ${ }^{1}$} & 0,830 \\
\hline & & & & & \multicolumn{2}{|c|}{ Acurácia (\%) } & 85,07 \\
\hline
\end{tabular}

${ }^{1}$ Coeficiente Kappa: $\mathrm{K} \leq 0,2$ - péssimo; $0,2<\mathrm{K} \leq 0,4$ - razoável; $0,4<\mathrm{K} \leq 0,6$ - bom; $0,6<\mathrm{K} \leq 0,8$ - muito bom; e $0,8<\mathrm{K} \leq 1$ - excelente. 
Tabela 3. Percentual de pixels corretamente classificados

\begin{tabular}{|c|c|c|c|c|c|c|c|}
\hline Classes & Cafezal & Mata/capoeira & Solo exposto & Pastagem 2 & Pastagem 3 & Pastagem 4 & Total \\
\hline Cafezal & 98,02 & 0,00 & 0,31 & 0,00 & 0,00 & 0,48 & 2,83 \\
\hline Mata/capoeira & 0,00 & 100,00 & 0,00 & 0,70 & 1,72 & 0,00 & 24,82 \\
\hline Solo Exposto & 0,00 & 0,00 & 82,16 & 0,00 & 0,00 & 48,01 & 22,51 \\
\hline Pastagem 2 & 0,00 & 0,00 & 0,16 & 97,46 & 0,14 & 0,16 & 18,94 \\
\hline Pastagem 3 & 0,00 & 0,00 & 1,88 & 1,27 & 89,13 & 5,26 & 18,45 \\
\hline Pastagem 4 & 1,98 & 0,00 & 15,49 & 0,56 & 9,01 & 46,09 & 12,45 \\
\hline Total & 100,00 & 100,00 & 100,00 & 100,00 & 100,00 & 100,00 & 100,00 \\
\hline
\end{tabular}

amostras corretamente classificadas alcançou resultado satisfatório (Tabela 2).

A classe que apresentou maior erro na classificação foi a pastagem, no nível de degradação muito forte (Pastagem 4), com 53,91\% dos pixels confundindo-se com as demais, principalmente com solo exposto (Tabela 3), em função da grande semelhança na resposta espectral, já que uma das características da pastagem no nível de degradação muito forte é justamente a ocorrência de solo descoberto, o que exigiu maior verificação de campo.

Por outro lado, verificou-se que mata/capoeira, cafezal e pastagem no nível de degradação moderado (Pastagem 2), respectivamente, com 100, 98,02 e 97,46\% dos pixels corretamente classificados, foram as classes que apresentaram os melhores resultados, conforme a Tabela 3. Esses resultados podem ser atribuídos a características como textura, brilho e resposta espectral, que distinguem cada uma das classes.

O predomínio de pastagens de capim gordura na Zona da Mata de Minas Gerais, originalmente coberta por vegetação florestal de Mata Atlântica, é conseqüência do intenso desmatamento a que esta região foi submetida, ao longo de décadas. Além das pastagens, que estão dispersas por toda a região, ocupando desde o topo das elevações até as margens dos cursos d'água, são encontrados também remanescentes florestais em vários estádios de conservação, culturas perenes, principalmente o café, e culturas anuais em menor escala.

Assim, a interpretação da imagem analisada neste estudo identificou duas classes de uso da terra (mata/capoeira e cafezal) e três níveis de degradação das pastagens: moderado, forte e muito forte (Figura 2).

Objetivando facilitar a identificação e classificação das classes de uso da terra e cobertura vegetal na imagem utilizada, foi adaptada a chave de interpretação visual, utilizada por Quinteiro (1997) na interpretação de aerofotografias não convencionais, no município de Viçosa, Minas Gerais (Tabela 4).

Em razão do tamanho reduzido de algumas áreas com diferentes usos ou cobertura vegetal, perfeitamente visíveis na imagem e características de regiões acidentadas, onde predominam pequenos agricultores, e da resolução espacial da imagem $(15 \mathrm{~m})$, foram necessárias verificações de campo para validar as informações obtidas.

A classe mata/capoeira corresponde às áreas com floresta primária ou secundária ou, ainda, capoeiras em estádios avançados de regeneração. Esta classe foi caracterizada sobretudo pela cor vermelho-escura, textura rugosa e forma irregular, estando dispersa por toda a área. Normalmente, ocupam as partes mais íngremes da paisagem e o topo dos morros (Baruqui, 1982), onde a declividade do terreno impede a utilização agrícola. Neste estudo não foi feita a distinção entre floresta primária, secundária e capoeira, já que este não era o objetivo principal do trabalho.

Outra classe de uso identificada na área é o cafezal, que apresentou resposta espectral diferenciada, em função da idade. As áreas que se apresentavam preparadas para o plantio do café, na época da obtenção da imagem, mostram cor azul claro, correspondente a solo exposto, enquanto nos cafezais mais jovens esta cor muda para alaranjada e, nos mais antigos, a cor é vermelho médio intenso. Uma característica marcante dessa classe, no entanto, é a sua forma regular, que ajudou a separá-la da pastagem no nível de degradação muito forte, que mostrou resposta espectral semelhante.

Não foram identificadas áreas expressivas com culturas anuais. Esta ausência está relacionada, sem dúvida, à época em que a imagem foi obtida, que coincide com o período posterior ao da colheita dessas culturas na região sendo,

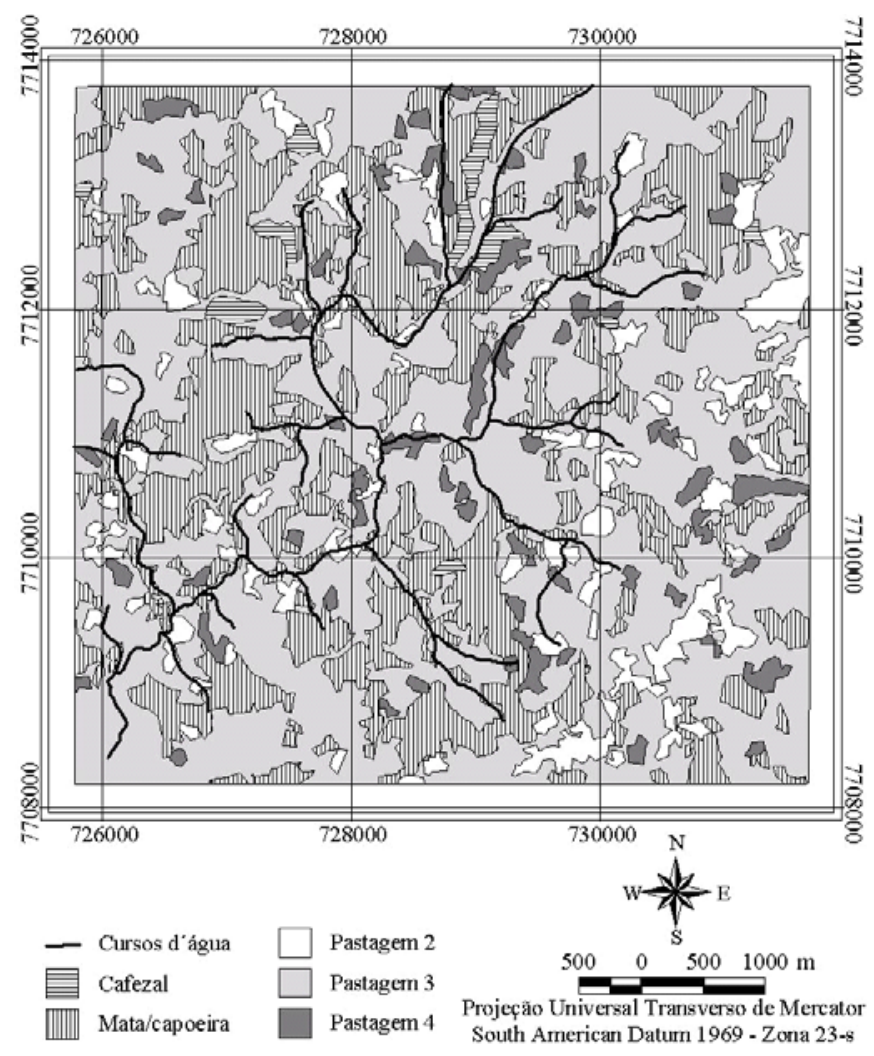

Figura 2. Resultado final da classificação da imagem 
Tabela 4. Chave de identificação visual da imagem: uso e cobertura vegetal

\begin{tabular}{|c|c|c|c|c|c|}
\hline Classes & Forma & Tamanho & Cor & Textura & Localização \\
\hline Cafezal & Regular & Pequeno a médio & $\begin{array}{l}\text { Alaranjado a vermelho médio } \\
\text { intenso }\end{array}$ & Suave & $\begin{array}{l}\text { Concentrada na porção norte da área, em relevo } \\
\text { menos acidentado }\end{array}$ \\
\hline Mata/capoeira & Irregular e contorno variável & Variável & Vermelho escuro & Rugosa & $\begin{array}{l}\text { Dispersa em toda a área, principalmente nos } \\
\text { topos de morros e nas partes mais íngremes }\end{array}$ \\
\hline Pastagem 2 & Irregular & Pequeno a médio & Rosada claro & Suave & $\begin{array}{l}\text { Dispersa em toda a área estudada, } \\
\text { independentemente do relevo }\end{array}$ \\
\hline Pastagem 3 & Irregular & Médio a grande & Verde médio & Suave a rugosa & $\begin{array}{l}\text { Dispersa em toda a área estudada, } \\
\text { independentemente do relevo }\end{array}$ \\
\hline Pastagem 4 & Irregular & Pequeno & Azul claro & Suave & $\begin{array}{l}\text { Dispersa em toda a área estudada, } \\
\text { independentemente do relevo }\end{array}$ \\
\hline
\end{tabular}

Fonte: Quinteiro (1997).

portanto, confundidas com algum nível de degradação de pastagem; outra possibilidade é que as áreas ocupadas por essas culturas eram muito reduzidas, dificultando sua identificação. Quinteiro (1997) também identificou poucas áreas com agricultura anual, fazendo um levantamento de uso da terra com aerofotografias não-convencionais, na região da bacia do Rio Turvo Sujo, que engloba a área do presente estudo.

Com relação aos níveis de degradação das pastagens, a imagem ASTER possibilitou a identificação de três níveis. As pastagens de Melinis minutiflora, Beauv., ocupam a maior parte da área e apresentam respostas espectrais distintas em função, basicamente, da presença de invasoras, cupins ou solo descoberto. A principal característica da imagem é a coloração, sendo as demais características muito semelhantes.

Assim, as pastagens que se encontram em um nível de degradação moderado (Pastagem 2), caracterizadas pelo baixo vigor e qualidade e baixa população, sem, no entanto, apresentar invasoras ou cupins, foram facilmente identificadas pela sua coloração rosada claro e textura suave (Tabela 4).

As pastagens identificadas no nível de degradação forte (Pastagem 3), caracterizadas pela grande presença de espécies invasoras, principalmente a Imperata brasiliensis, Trin. (capim sape), mostram coloração verde médio e textura variando de suave a rugosa (Tabela 4) podendo referida característica estar relacionada à presença de espécies invasoras em grande quantidade.

As pastagens que se encontram no nível de degradação muito forte (Pastagem 4), são caracterizadas, além da baixíssima qualidade, vigor e população, pela presença de áreas significativas de solo descoberto, denominados pelados, muitas vezes associadas a grandes quantidades de cupinzeiros. Em função disso, na imagem apresentam uma coloração azul claro, em resposta a esta condição.

Não foram identificadas áreas de pastagens no nível de degradação leve, ou seja, apresentando vigor e qualidade.

Embora a região conte com o apoio tecnológico de universidades e centros de pesquisa, alguns fatores, como relevo muito acidentado, solos pobres, falta de assistência técnica, baixa capacidade de investimento dos pequenos produtores rurais (grande maioria) e crédito rural relativamente caro, podem explicar o baixo nível de tecnologia empregado que, por sua vez, contribui significativamente para a ausência de pastagens de qualidade e para a magnitude do processo de degradação na região.
A Tabela 5 apresenta os resultados da quantificação de áreas das classes de uso da terra e cobertura vegetal natural, com base nas imagens de 2001 e posterior verificação de campo realizada em junho de 2003.

Do total de 3.314 ha avaliados, aproximadamente $70 \%$ correspondem às áreas de pastagens, 28,73\% pertencem à classe mata/capoeira e $1,54 \%$ à classe cafezal.

A porcentagem de remanescentes florestais identificados é superior aos $25 \%$ estabelecidos pela Organização das Nações Unidas como ideal para o desenvolvimento de uma agricultura auto-sustentável (Wolski, apud Quinteiro, 1997). Quinteiro (1997) encontrou o valor de 21\% para a unidade florestas na microbacia do Rio Turvo, destacando que esta é composta, além das matas nativas, pelos povoamentos florestais de espécies exóticas. $\mathrm{Na}$ área de estudo os povoamentos com espécies exóticas são raros e limitados a pequenas áreas. Os remanescentes florestais ocorrem em todas as classes de relevo; no entanto, são mais expressivos em áreas de relevo forte ondulado, principalmente no topo das elevações (Baruqui, 1982), e relevo plano, margeando os córregos como áreas isoladas.

Os cafezais ocupam $1,54 \%$ da área de estudo, situandose nas áreas de relevo forte ondulado (segmentos convexos) e no topo plano dos morros, nos quais os Latossolos se fazem presentes e, ainda, nos segmentos côncavos, onde ocorrem os Cambissolos.

As pastagens identificadas no nível de degradação moderado (Figura 3A) ocupam 8,21\% da área avaliada e ocorrem mais freqüentemente em áreas de relevo plano, características de Argissolos, com fertilidade natural e retenção de umidade mais elevadas, condições que favorecem um desenvolvimento melhor das diversas espécies vegetais, em particular, as pastagens. Estão situadas também em áreas de relevo forte ondulado, sobretudo nos segmentos côncavos

Tabela 5. Quantificação das classes de uso e cobertura vegetal natural

\begin{tabular}{ccc}
\hline Classes & Área (ha) & $\%$ \\
\hline Cafezal & 51 & 1,54 \\
\hline Mata/Capoeira & 958 & 28,73 \\
\hline Pastagem 2 & 272 & 8,21 \\
\hline Pastagem 3 & 1.871 & 56,46 \\
\hline Pastagem 4 & 168 & 5,07 \\
Total & $\mathbf{3 . 3 1 4}$ & $\mathbf{1 0 0 , 0 0}$ \\
\hline
\end{tabular}


A

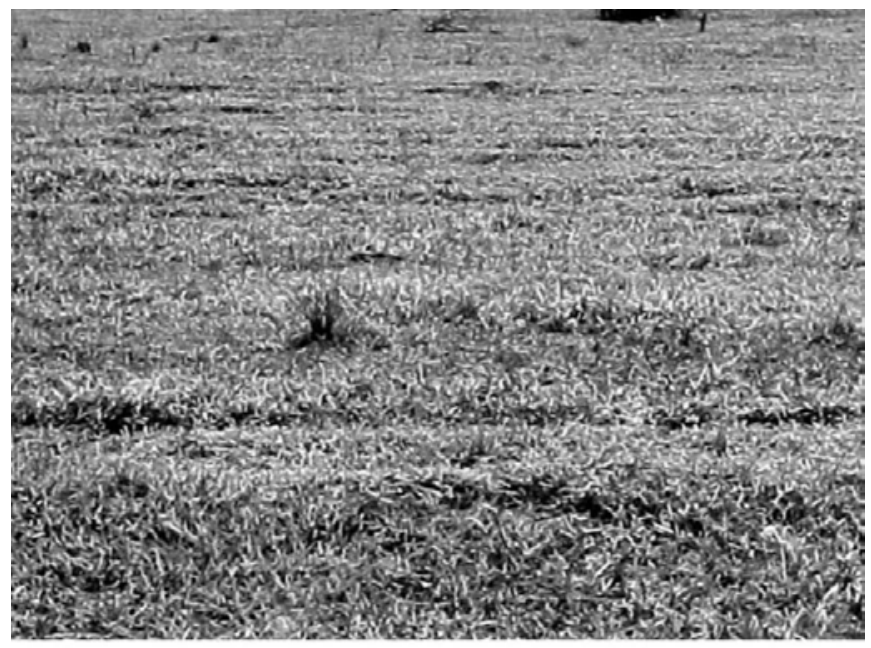

Pastagem 2

C

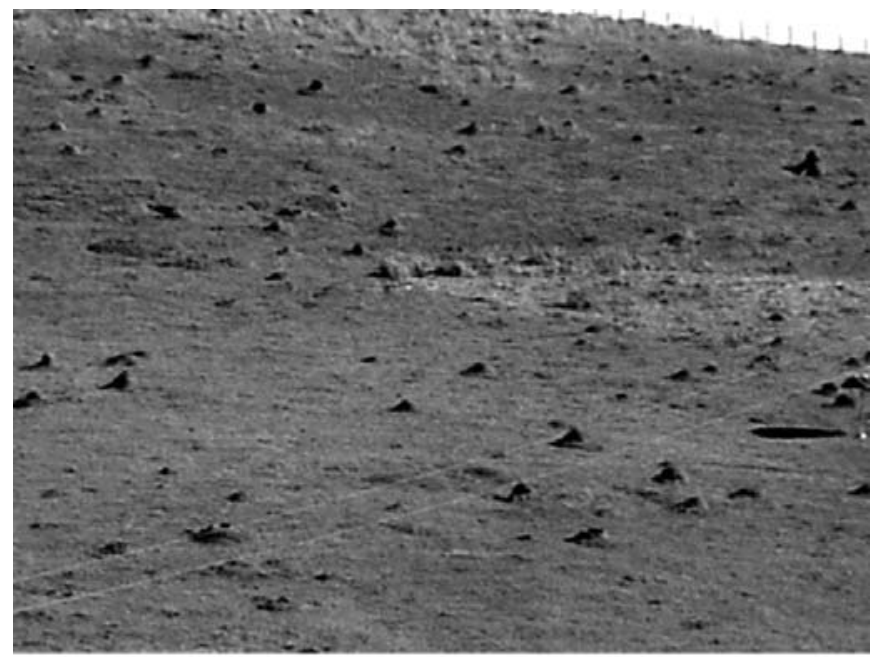

Pastagem 4
B

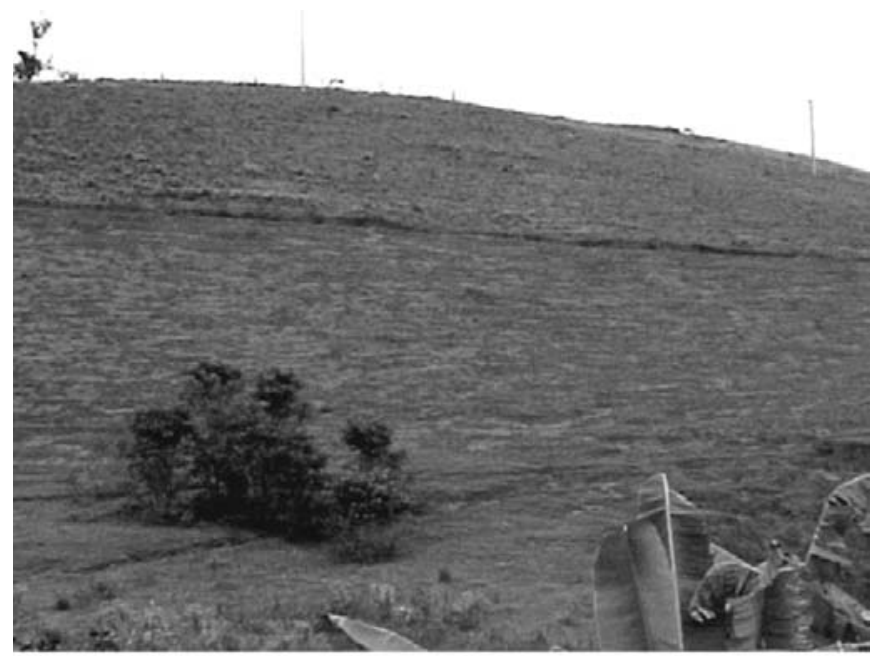

Pastagem 3

D

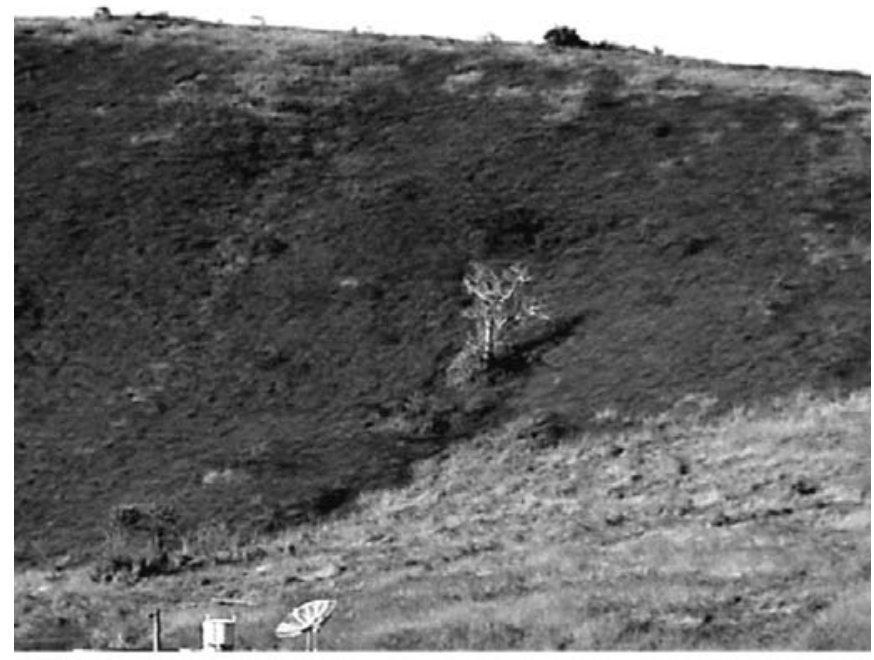

Pastagem 4

Figura 3. Pastagem no nível de degradação moderado (A), forte (C) e muito forte (B e D)

da paisagem, que retêm mais água e acumulam nutrientes provenientes das partes mais íngremes. De maneira geral, o superpastejo impede o melhor desenvolvimento das pastagens nessas áreas.

As pastagens que se encontram no nível de degradação forte (Figura 3C) ocupam 56,46\% da área avaliada e ocorrem predominantemente em áreas de relevo forte ondulado nos segmentos convexos da paisagem. A principal característica dessas áreas é a presença de espécies invasoras, em especial a Imperata brasiliensis, Trin. Pimentel et al. (1982), identificaram que a freqüência dessa espécie de invasora nas pastagens naturais do planalto de Viçosa, Minas Gerais, era maior nos segmentos convexos da paisagem, que se deve ao fato de, tanto a presença de Melinis minutiflora, Beauv., quanto da Imperata brasiliensis, Trin., apresentaram corre-

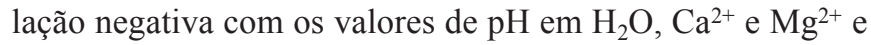
saturação de bases, além de correlação positiva com os valores de $\mathrm{Al}^{3+}$ e saturação de alumínio, condições estas facil- mente encontradas nesses segmentos.

As pastagens no nível de degradação muito forte (Figura 3B e D) correspondem a 5,07\% da área de estudo e estão localizadas, preferencialmente, em áreas de relevo forte ondulado, indistintamente nos segmentos convexos e côncavos, embora mais evidentes nos segmentos convexos.

Nessas áreas de relevo forte ondulado, o déficit hídrico mais pronunciado e o uso indiscriminado do fogo contribuem sensivelmente para que a cobertura vegetal seja eliminada (Pimentel et al., 1982).

Segundo Oliveira et al. (1996), as alternativas tecnológicas desenvolvidas para o restabelecimento da capacidade produtiva das pastagens passam, em sua grande maioria, pela correção e fertilização do solo, práticas conservacionistas e respeito à legislação ambiental, associados à sua movimentação com implementos agrícolas, operações bastante dificultadas na região da Zona da Mata de Minas Gerais, em virtude do relevo muito acidentado. 
É conveniente se destacar que as pastagens, quando não degradadas promovem, com alta eficiência, a ciclagem de nutrientes, a captação de carbono da atmosfera e a redução dos processos de erosão; desta forma, neste estudo, com a identificação de três classes de degradação, torna-se possível inferir quais dessas atividades (ou se todas) estão sendo afetadas.

\section{CONCLUSÕES}

1. A imagem do sensor ASTER mostrou-se capaz de discriminar satisfatoriamente as diferentes classes de uso da terra na área estudada, a saber: mata/capoeira, cafezal, solo exposto e pastagem.

2. A imagem possibilita a identificação de três níveis de degradação das pastagens de Melinis minutiflora na região da Zona da Mata de Minas Gerais (moderado, forte e muito forte).

3. As classes que apresentaram maior erro de omissão foram: a pastagem no nível de degradação muito forte (Pastagem 4) e solo exposto com 53,91 e 19,56\%, respectivamente.

4. As classes que mostraram maior percentual de acerto na classificação, foram: pastagem no nível de degradação moderado e mata/capoeira, respectivamente, 97,46 e $100 \%$.

\section{LITERATURA CITADA}

Assad, E. D.; Madeira Neto, J. S.; Moreira, L. Uso de padrões radiométricos para separação de quatro espécies de gramíneas em condições de Cerrado. Pesquisa Agropecuária Brasileira, Brasília, v.26, n.10, p.1625-1633, 1991.

Barcellos, A. O.; Viana Filho, A.; Balbino, L. C.; Oliveira, I. P.; Yokoyama, L. P. Produtividade animal em pastagens renovadas em solo arenoso de cerrado. In: Reunião Anual da Sociedade Brasileira de Zootecnia, 34, 1997. Juiz de Fora. Anais... Juiz de Fora: SBZ, 1997, v.4, p.207-209.

Baruqui, F. M. Inter-relações solo-pastagens nas regiões Mata e Rio Doce do Estado de Minas Gerais. Viçosa: UFV, 1982. 119p. Dissertação Mestrado

Brites, R. S.; Soares, V. P.; Ribeiro, C. A. A. S. Verificação da exatidão em classificação de uma imagem orbital mediante a utilização de três índices. Revista Árvore, Viçosa, v.20, n.3, p.415-424, 1996.

Carvalho Filho, A. Caracterização mineralógica, química e física de solos de duas unidades de paisagem do planalto de Viçosa, MG. Viçosa: UFV, 1989. 114p. Dissertação Mestrado

Carvalho, M. M. Recuperação de pastagens degradadas em áreas de relevo acidentado. In: Dias, L. E.; Mello, J. W. V. (eds.). Recuperação de áreas degradadas. Viçosa: UFV-DPS/Sociedade Brasileira de Recuperação de Áreas Degradadas, 1998. p.149-161.
ESRI - Environmental Systems Research Institute. ArcView GIS. The geographic information system for everyone. New York, 1996. n.p.

Foody, G. M. On the compensation for chance agreement in image classification accuracy assessment. Photogrametric Engineering and Remote Sensing. Bethesda, v.58, n.10, p.1459-1460, 1992.

Golfari, L. Zoneamento ecológico do Estado de Minas Gerais para reflorestamento. Belo Horizonte: PRODEPEF/PNUD/FAO/IBDF/Bra-45, 1975. 65p. Série técnica 3

Hernández, P. F.; Ponzoni, F. J.; Pereira, M. N. Mapeamento da fitofisionomia e do uso da terra de parte da Bacia do Alto Taquari mediante o uso de imagens TM/Landsat e HRV/SPOT. Pesquisa Agropecuária Brasileira, Brasília, v.33, n. especial, p.1755-1762, 1998.

Moreira, L.; Assad, E. D. Segmentação e classificação supervisionada para identificar pastagens degradadas. Workshop Brasileiro de Geoinformática, 2, 2000, São Paulo. Anais... São Paulo: SBC, 2000. 15p.

Naime, U. J. Caracterização de solos de terraços nas Zonas da Mata e Rio Doce, Minas Gerais. Viçosa: UFV, 1988. 76p. Dissertação Mestrado

Nascimento Júnior, D.; Queiroz, D. S.; Santos, M. V. F. Degradação das pastagens e critérios para avaliação. In: Peixoto, A. M.; Moura, J. C.; Faria, V. P. (eds.). Simpósio Sobre Manejo de Pastagem, 11, 1994, Piracicaba. Anais... Piracicaba: FEALQ, 1994. 325p.

Oliveira, I. P.; Kluthchcouski, J.; Yokoyama, L. P.; Dutra, L. G. Sistema Barreirão: recuperação/renovação de pastagens degradadas em consórcio com culturas anuais. Goiânia: EMBRAPA-CNPAF, 1996.90p. Documento 64

Pimentel, J. C. M.; Júnior, D.; Resende, M. Caracterização das pastagens naturais das pedopaisagens côncava e convexa do Planalto de Viçosa, Minas Gerais. Revista da Sociedade Brasileira de Zootecnia, Viçosa, v.11, n.1, p.168-187. 1982.

Price, K. P.; Pike, D. A.; Mendes, L. Shrub dieback in a semiarid ecosystem: the integration of remote sensing and geographic information systems for detecting vegetation change. Photogrammetric Engineering and Remote Sensing, Bethesda, v.58, n.2,p.455-463. 1992.

Quinteiro,F.Q.L.Levantamento do uso da terra e caracterização de ambiente da bacia hidrográfica do Rio Turvo Sujo com a utilização de aerofotos não-convencionais. Viçosa: UFV, 1997.91p. Dissertação Mestrado

Research Systems, Inc. Envi, 3.5. The Environment for visualizing images. Colorado, 2001.n.p.

Rosenfield, G. H.; Fitzpatrick-Lins, K. A coefficient of agreement as a measure of thematic classification accuracy. Photogrammetric Engineering and Remote Sensing, Mayland,v. 52, n. 2, p.223-227, 1986.

Sano, E. E.; Chaves, J. M.; Bezerra, H. S.; Feitoza, L. Identificação dos principais tipos de pastagens cultivadas do Cerrado a partir de Sensoriamento Remoto. International Symposium: Soil Functioning under Pastures in Intertropical Areas, 2000, Brasília. Anais... Brasília: Embrapa Cerrados - IRD, 2000. CD-Rom.

Spain, J. M.; Gualdrón, R. Degradación e rehabilitación de pasturas. In: Lascano, C.; Spain, J. M. (eds.). Establecimiento y renovación de pasturas. Cali: CIAT, 1991. 426p. 